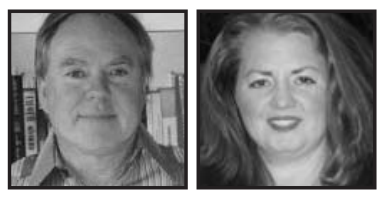

\title{
Working the Image: Unearthing Aspects of Teachers' Lives Through Arts-Engagement
}

\author{
P. Bruce Uhrmacher \& Cassandra Trousas, University of Denver
}

\section{ABSTRACT}

This paper presents a research method and some of the results thereof that asked teachers to engage in a reflective arts inquiry. This inquiry led teachers to plumb the depths of their own unconscious and bring what lies beneath into conscious awareness, leading to deeper reflection and ontological knowing. The researchers suggest that such awareness leads to improvement of classroom life for teachers and their students.

\section{The Arts and Consciousness}

$\mathrm{n}$ recent years the aims of education have become narrowly defined in terms of the content being taught to children while teaching has become more restrictive in its methods. Indeed, too often in today's world, education is mired down in the details of high-stakes testing and the pressure to improve a constricted vision of student achievement (Fullan, 2007). Moreover, although there are notable exceptions (e.g., see Tyler, 1958; Grumet 1976, 1988; Connelly \& Clandinin, 1994; Mayes, 2005), teachers are rarely offered the time and the space to ruminate on the deeper aspects of their thinking and feeling selves in schools. These realities result in a shallow approach to education.

The purpose of this paper is to present a research method that leads to a deeper understanding of the dynamics of classroom life for teachers. Our effort rallies around the idea that classroom communities are in need of a kind of communicative engagement that opens up a space for reflection (Shöen, 1983) and for what Donald 
Oliver and Kathleen Gershman (1989) refer to as "ontological knowing"—feelings and sensory experiences that may be known and captured-though never fullythrough poetic and narrative forms of statements. ${ }^{1}$

There are, we contend, elements of classroom life that have a strong influence on teaching and learning but that are often left unexamined and unspoken. They address that which is difficult to ascertain: the symbolic, the unconscious, and even the fantasy lives of teachers and students (McDonald, 1992), which together contribute to ontological knowing (Oliver \& Gershman, 1989). Our attempt is to construct an approach that aids teachers and students in examining the undercurrents of classroom life and to bring ideas and feelings to conscious awareness for the purposes of achieving depth in learning and being. We believe that engagement with the arts is a rich space in which this can be done.

Our approach, which we currently call "reflective art inquiry," helps to un cover the unconscious, defined as that which is beneath the surface but can be brought to consciousness. While some scholars make a distinction between the unconscious, preconscious, and subconscious (Easthope, 1999), we do not enter this debate but look to all three as that which can be plumbed and brought into awareness for the benefit of teachers and students. This approach brings the unconscious into conscious awareness.

In addition, reflective art inquiry helps us explore the symbol systems that guide our knowing lives. We introduce a term, seeing as to explain the ways in which we cloak the world in symbol systems, and bring such seeing as experiences into consciousness. As humans, we engage with the world and immediately upon experiencing something label it. This system allows us to efficiently process much of what we come into contact with on a daily basis. Yet, seeing as does not allow us to truly seewe frequently mistake the label for the real thing. Reflective art inquiry attempts to break through symbol systems and to get beyond them to something new.

We follow James Hillman's (1975) ideas of the fantasy-image which can be defined as, "both the raw materials and finished products of the psyche" (p. xi). According to Hillman, "every notion in our minds, each perception of the world and sensation in ourselves must go through a psychic organization in order to 'happen' at all. Every single feeling or observation occurs as a psychic event by first forming a fantasy-image" (p. xi). For Hillman, the originating space for fantasy-image is the imagination which he contends, "... is the most important function of the psyche ..." (as cited in Davis, 2003, p. 101). Many psychologists refer to "fantasy" as the images of 
psychotics and "phantasy" as the underlying images produced by average-waking people. We use the word image alone in an effort to reduce the connotations associated with either rendering of the word fantasy.

We believe Hillman's idea of the imagination-originating image has implications for classroom life in that, if viewed in this light, images are circulating in the minds of teachers and students at any given moment in the classroom and thus could be affecting student learning. Moreover, images created by and in the imagination can manifest as larger practical intentions and the realization of one's "calling" (Hillman, 1996). In our analysis images are the ground from which intentions, objectives, aims, and goals all arise. We see our reflective art inquiry as offering opportunities for teachers and students to examine their own images and move toward a realization of deeper knowing and individual potential.

\section{The Reflective Art Inquiry Process}

The ideas contained in this paper are a working revision of ideas by Uhrmacher (1993, 1995) and Uhrmacher and Trousas (2007) over the past fifteen years. Initially called Presentational Action Research and redefined as Arts-based Action Research and now Reflective Art Inquiry, our approach continues its trajectory focusing on how engagement with the arts can open up spaces for reflection, transformation, and understanding that can affect teaching and learning experiences in schools. We are content with any of these titles to describe our work. But the last designation represents our most current efforts and characterizes the ways in which arts-engagement stimulates a number of inquiries to uncover aspects of educational environments that lead us toward different types of action. We discuss this point in the Enactment section of this paper.

Why use the arts to unearth symbol systems, images, and the unconscious? Arts engagement offers human beings a limitless capacity for exploration and growth and is a natural conduit to the unconscious because it allows individuals an alternative space for inquiry into the self. In addition, working with art is a relatively safe place to try to understand the images and symbols alive in our unconscious selves. In this respect, working with art is an indirect approach to ontological knowing. In many ways the images created speak for themselves. This conversation between the individual and the images of the imagination (Hillman, 1989) can result in a deeper and freer experience of knowing. 
Participants who engage in our reflective art inquiries are led through an artistic process of creating a paper collage or Play-Doh sculpture. While any medium could be used in these activities, we chose collage and Play-Doh because both offer easy entrance to ideas and images. Participants in our reflective art inquiries have been asked to create a work of expressive art that would aid them in engaging with their unconscious and fantasy-images. Once the work is completed to the satisfaction of the maker, participants and researchers examine the works with an eye towards the three goals of this approach: to allow what is beneath consciousness to be made conscious, to break through symbol systems in terms of seeing as, and to examine one's own images as the work of the imagination.

Participants involved in our reflective art inquiries are led through a series of steps. These include: "imaging," reframing," and "enacting."

Imaging refers to the specifically artistic component of this approach and begins with participants forming an image in their minds. They are then asked to translate that into some material medium to form a representation of their experiences, intuitions, and understandings, in this case a paper collage or Play-Doh (or both). During the construction process, through the participants' manipulation of words and images, which could include symbolic renderings of memories, insights and theoretical comprehensions emerge. Dewey, in his classic work on aesthetics, points out that, "When excitement about subject matter goes deep, it stirs up a store of attitudes and meanings derived from prior experience. As they are aroused into activity they become conscious thoughts and emotions, emotionalized images" (1934, p.65).The teacher products are not appraised for their artistic merits, but rather are used as devices to delve into ideas and images.

Reframing refers to the reflective stage of the art inquiry in which participants discuss their art works with each other. This phase represents a metaphorgenerating or archetype-generating process. In reframing, one discusses the myriad "seeing as" possibilities. In Hillman's (1989) view any image can be considered archetypal;" "by attaching archetypal to an image, we ennoble or empower the image with the widest, richest, and deepest possible significance" (p. 26). Participants begin by observing their own artwork, examining its every nuance. Then, as a group, participants closely examine all aspects of one another's works and analyze them. They discuss the different images and words used in the collage and what kinds of archetypal stories or metaphors emerge. Together, participants have a conversation about the artwork to build the metaphors or archetypes that raise awareness of the unconscious aspects of the collage and/or Play-Doh creation. In addition, participants focus 
on the symbol systems used in the collage and work to break through these images toward something new.

Enacting is defined as the participants' reactions to their art works (and to the process of making them). It refers to the possibility that participants will undergo change in their perceptions of the issue, problem, or question ruminated upon. Teachers engaged in education are continually faced with ambiguous, contradictory, and often unconscious feelings that affect their work lives. By helping teachers tap into their emotions and feelings, this arts-based approach provides the impetus for enlarged perspectives and a coming into awareness of their deeper unconscious selves in the classroom.

\section{Data Sources and Results}

The following describes the results of one project that took place in the fall of 2007 with thirteen teachers - some elementary and some secondary. Participants took part in the process mentioned above and the conversations were hand-recorded. Our goal was to uncover teachers' unconscious feelings, the "seeing-as" symbol systems being employed, and the images that may have provided the umbrella for all that takes place. This paper describes, interprets, and thematicizes the artistic products and conversations about them, much in the style of an educational connoisseur (Eisner, 1997).

Participants in the project had roughly two hours to create collages and/or Play-Doh sculptures (some participants combined both materials) and to have a discussion about them. Participants were told they could begin in one of two ways: they could play with the materials until an image formed or they could begin with a particular educationally-oriented problem, issue, or question that they would like to explore. There were eight females and five males who participated in the study; three students were students of color. In selecting cases to focus on for this paper, we observed that some students explored problems that remained diffuse through the creation and the discussion. Some participants focused very narrowly on a problem making it less salient for our purposes. But some participants were able to articulate a problem, create a telling image, and astutely come to a new realization as a result of the exercise. Admittedly, for those participants who had a less-than-satisfactory experience, the fault is ours not theirs. With more time, more processing, and more discussion, we believe that these participants too would have had an enhanced experience. 
Several kinds of issues, problems, and questions emerged from this project. Some participants focused on their choice of education as a career. Some thought specifically about "kids" in their classrooms and how they as teachers could help these students. One teacher reflected on how he might help students to write better. Another teacher thought about ways to get students in touch with books. And another teacher wanted to reach a particular student who had issues about trust. Finally, some participants reflected upon themselves and the kinds of qualities they possessed or wished to possess as educators. For example, one participant wondered about her own sense of creativity.

While all of the above were attractive possibilities to explore, we noticed that three female teachers, in particular, engaged in an educational tension-one that was brought to light through the reflective art inquiry process. Thus, for this paper, we focus on these three participants and what their stories have to tell. Below we present the Imaging and the Reframing sections for these participants, Harper, Shay, and Martha. Afterwards we discuss the theme that resulted from each of these three and the implications for enactment.

\section{Exploring Educational Issues and the Unconscious Through Art}

\section{Harper2: Imaging}

Harper is a young Caucasian woman in her early twenties finishing her Masters degree in Educational Leadership while teaching art at a public school. Below is a description of her project from our notes:

Harper used magazine paper and rolled the pages into a round base, about 6 inches in diameter. She then had 6 rolled magazine columns, about 11 inches long, leading up from the base leaning at a slant upward, creating a point and on top of the point she created a fluttery paper bird of various colored magazine pages. Since she was using magazine paper with both colorful and black and white advertisement images, as well as pages with black and white type print on them, the sculpture had a glossy sheen. The bird itself was an abstract image, of white-blue-brown and red colors co-mingled. The wings of the bird were the size of women's hands and draped over the columns covering the top quarter of the sculpture. The entire sculpture 
was approximately 12 inches tall and about 6 inches wide. Interestingly, no glue was used in this creation. The various components of the sculpture were put together using scissors to cut slats and then fitting the pieces together.

\section{Reframing}

"Tell us about your project."

Harper says, "I was in a staff meeting with art and theater teachers. They talked about how they wanted to do amazing things but that they couldn't because of all kinds of different constraints like: Administration, Time, Schedules, Money, Politics, and even the Curriculum." Harper looks at her sculpture as she talks, "They wanted to do amazing things but they were tied to different places."

"These things tie the bird down," said the facilitator. She nodded. "So, your representation is "a bird that wants to fly and wants to be free but there are all these concerns tying the bird down." Harper agreed.

Harper asks the question: "Can it get free ever?" There is quiet in the room as everyone looks at the sculpture.

Then the facilitator says, "These same things could be seen as holding up the bird. Instead of thinking about the 'ties' as restraints tying down the bird, these things, like administration and schedules, can be seen as things that support the bird or 'hold it up'."

Harper agrees. She didn't think about it that way but she agrees that it is plausible to look at the base of the image holding the bird up as well as holding it down. In a follow-up conversation she commented, "I was thinking negatively about the institutions that make our jobs possible and it was good to be reminded that there is a flip side..."

\section{Shay: Imaging}

Shay is a woman of African-American descent in her early twenties working toward a Master's degree. We begin by introducing her project below from our notes:

A brilliant pink box, approximately $2 \times 2 \times 2$ made up of a floor, four walls and open top made of Play-Doh. The box is a perfect square. Inside the box is a 
figure fashioned out of Play-Doh that represents Shay, "I look sort of like an alien but that's okay," and the head of the figure is split representing "the two sides of her thinking." Extending to the right and the left from the center of the outer wall of each side of the box is a red pipe cleaner. The pipe cleaner extends from the center of the side of the box slanting down to the table. Both pipe cleaners are approximately 9 inches long. At the point at which the pipe cleaner meets the table, the student has placed a picture from a magazine as if the pipe cleaner is a connection from the box that contains her figure to the image in the magazine picture lying flat on the table. The left side of the sculpture looks the same as the right side except that the images underneath the end of each pipe cleaner are different. On the left side is an image of a shovel with the words "free all access pass." Next to the shovel is a jailbird, a figure in black and white stripes and handcuffs, seated. The word "NyQuil" is pasted over the figure's head. On the right side is a woman leaping with joy over water. The woman's arms are extended upward. Her left leg is bent forward at the knee. Her right leg is extended backward.

\section{Reframing}

About her image, Shay says, "The image represents my internal conflict and my goals and intentions as an educator." My questions were: "How do I find balance? What direction should I go in my teaching?" As we all look at her sculpture, Shay continues talking, "The pipe cleaners are a tight rope on either side. On the one side are the standards, expectations, and test preparation."

The room is quiet as Shay reflects on her sculpture, "I get a lot of people telling me I am doing a great job preparing students, but this leaves me unfulfilled." Then she looks at the right side of her sculpture, "On the other side, if I let [the students] be free and uninhibited they won't test well and they will be tagged as 'failures' and I will let them down. I feel that I am restricting them in their thinking although [I am] keeping their scores up, but I'm not allowing them the freedom they need....My work is contradicting my ideas of teaching.... am in a small space, the school districts want certain things and I am trying to rise above the water."

Someone in the room asks what would happen if the box was turned over with the figure standing on top. Commenting on the figure in the middle of the box in the middle of these tight ropes representing opposite intentions and aims of schooling, Heather says, "You look like a bridge." 
"Yes," says the facilitator elaborating on Heather's comment, "You're a bridge builder. That is, you are the one that ties the whole project together." Shay nods.

As before, when discussing Harper's project, a reframing of the image was put forth and everyone in the room seems to have an "aha" moment when reflecting upon the new possibility presented for discussion. We do not mean that the "aha" moment provided a revelation allowing for immediate re-assessment of the educational enterprise or a new sense of how to get things done. Rather, the "aha" moment is a reflective observation. In a follow-up questionnaire, Shay elaborates on her thinking. She notes that the discussion provided "keen observations." Moreover,

I guess the struggle I realized is that I need to find that middle ground but it continually feels like the act of tug-a-war, because there is always a force pulling from either direction, one usually stronger than the other, not enabling any equilibrium.

About the project, Shay says,

It enabled me to really reflect on an internal conflict I've experienced for some time now and I was able to articulate it in a different way that was good for me because it helped me put how I see my future as an educator into perspective. The feedback given helped me see my conflict in a more optimistic way, maybe not so much as a problem but a cause.

Moreover, her sculpture reminds her:

about how education is deemed as a molding profession, one in which you develop the minds of young people and prepare them to be critical selfmotivated thinkers. However, it seems that districts are preparing teachers to be the exact opposite, to be functional (only in process) disseminators of a greater agenda with little room to be vocal in opposition of that agenda.

\section{Martha: Imaging}

Finally, Martha is a young Caucasian woman also in her early twenties. She is working on her Masters degree but she is not currently teaching. When the project ended Martha took her collage home with her and so our notes of her sculpture are limited. Nonetheless, our notes had recorded a fairly fleshed-out description: 
Martha created a collage, an egg-shaped paper collage divided into four sections. In the upper left-hand quadrant is a blue butterfly cut from a magazine and on the right hand side, taking up the whole right side of the eggshaped collage, is a picture of an outdoor scene with semi-transparent thick vertical lines over it. In the lower left-hand quadrant there is a picture of another outdoor scene with horizontal lines crossing it.

\section{Reframing}

"The question I am asking," says Martha, "is can I teach inside? Can I be the teacher I am outside, inside?" She said, "I need to make a decision; I have to make a decision soon." Outside Martha is a teacher who is open and free. She can spread her wings. Inside she feels trapped.

The student sitting next to Martha notices that the bars are "a symbol of what is holding you inside, holding you back from the external space."

But the facilitator adds, "It looks like you could move in and out. The bars are see-through so they might not actually be holding you in."

The student sitting next to Martha adds, the "butterfly symbolizes change."

"Yes, a position of change," says the facilitator.

Once again the issue of balancing freedom and constraint is brought into the scene involving Martha and her collage. Martha, faced with a dilemma related to her career, to her love of the outdoors, and to what she perceived as the confining nature of teaching in an indoor educational environment, directed all of her attention toward the limiting facet of this particular issue in her educational life. Through a discussion of one aspect of her image-the transparent "bars" laid over the chosen picture images - she was invited to notice how her unconscious might be providing her an alternative possibility: that movement in and out, between and through the confining aspect of her teaching life may provide its own answer to her dilemma. Therefore it is not an either/or proposition but a, "this too," idea which might propel her forward in her perceptions of her career. 


\section{Enacting: Implications of the Reflective Art Inquiry Process}

Imaging and reframing are the artistic and analytic elements of the reflective art inquiry process; enacting refers to the active component. However, the action component of reflective art inquiry, born out of ideas of action research, can be explored in multiple ways. Once participants come to a resting place in the imaging and reframing aspects of the process, the next question to be asked is: "what next"? Within the framework of this project, we suggest that participants have at least four ways to respond to or enact what has been formed, uncovered, and reframed as a result of the reflective art inquiry process.

\section{Reflective Enacting}

As indicated earlier, the reflective art inquiry process is an outgrowth of earlier work called arts-based action research that combines arts-based educational research and action research for deeper understanding of educational phenomena (See Uhrmacher 1993, 1995; Uhrmacher \& Trousas, 2007). While action researchers complete their investigations with an action phase, reflective art inquiry casts action in a different light. Teachers who have explored educational issues through the reflective art inquiry process may choose instead to change their thinking or their feelings about a situation rather than the situation itself which may prove to be unyielding to external force or change. In such cases, action may not be the most salient path to follow. Joseph Schwab (1972) points out:

Practical problems can be settled by changing either the state of affairs or our desires. The latter kind of solution is as legitimate as the former. It follows, then, that practical problems intrinsically involve states of character and the possibility of character change. (p. 289)

This type of enacting refers to the possibility that arts-based action researchers or, in our case teachers engaged in reflective art inquiries, change their feelings or desires about their professional situation. Teachers and others engaged in education are continually faced with ambiguous, contradictory, and partly unconscious feelings that impact their work lives. By helping teachers look at their artistic images differently, in some cases seeing the negative aspects of the image in terms of their positive possibilities, they are able to enlarge their perspectives. In this way, teachers may respond to classroom practices by seeing it anew, rather than by taking on new actions. 


\section{Ontological Enacting}

Teachers engaged with reflective art inquiries might also respond to the process by changing the way they think about the universe and their roles in it-an ontological form of enacting. Ontological enacting refers to the kinds of meanings ascertained through religious, cosmological, and holistic inquiries. Such meanings are characterized by a feeling of entering into something's essence or of relational knowing and seeking universality (Oliver \& Gershman, 1989). By deliberately engaging with the unconscious and bringing to consciousness images and feelings otherwise neglected, teachers may engage with ideas larger than themselves that hold more universal meaning for them.

Ontological enacting could situate the reframing aspect of reflective art inquiry within what is universal and might then become an additional space in which to explore the depth of the soul, looking inside and out for "the imaginative possibility in our natures, the experiencing through reflective speculation, dream, image, and fantasy - that mode which recognizes realities as primarily symbolic and metaphorical" (Hillman, 1975, p.xvi). Through the reflective art inquiry process, teachers are invited to grapple with the larger overarching narratives brought into consciousness through their engagement with art which may add to their ontological knowing.

\section{Living in the Tension}

A third way teachers can respond or enact to what is brought to consciousness in the reflective art inquiry process is simply to live in the existing tension that has emerged from the reframed images. Caught between difficult realities and dichotomies in educational milieus, there may not be a self-evident solution to problems, as Parker Palmer (2004) points out:

In particular, we must learn to hold the tension between the reality of the moment and the possibility that something better might emerge... I mean the tension between the fact that we are deadlocked about what to do and the possibility that we might find a solution superior to any of those on the table. (p. 175)

Teachers, who may have a better understanding of an educational issue, problem, or concern as a result of reflective art inquiries, may need to remain at this resting place, of living in the tension, until a solution emerges or different circumstances arise allowing change to take place. 
The reflective art inquiry process creates a space for living in the tension and promotes a community of reflective teachers even if solutions are not apparent or tangible:

When we listen to another person's problems, we do not leap to fix or save: we hold the tension to give that person space to hear his or her inner teacher. We learn to neither invade nor evade the reality of each other's lives but rather to find a third way of being present to each other. (Palmer 2004, p. 182)

Though the current educational climate may be fraught with difficulty, teachers need not back away from exploring their own educational concerns for fear of discovering problems with no solutions; rather, they can live in the tension and continue to teach with purpose and hope.

\section{Changing the Environment}

A fourth way teachers can enact what has been brought to consciousness is to critically act and change the educational setting in some personally meaningful way. This might require what Freire (1970) refers to as praxis, "that is ... reflection and action directed at the structures to be transformed" (p. 107). More closely aligned to traditional forms of action research, instigating changes to the environment or engaging in "praxis" may occur in small or more radical ways but would be a response to the concerns that were brought to consciousness by the reflective art inquiry process.

Teachers, who have uncovered through their images some part of their unconscious workings, may have a renewed sense of where their energies need to be directed. For instance, we can imagine Shay making curriculum choices for her students that strive for balance between outside pressures and her internal ethic of how students should be taught; she could conceivably act more like the metaphoric bridge discussed during the reframing analysis of her sculpture. We can imagine Harper, who was able to reframe the constraints she perceived in the educational system as forms of support instead, participating more actively in the structure of her school as a result of her new position. And finally, we might imagine Martha internalizing the transparent "bars" of her teaching life and actively seeking a teaching position where she can physically move both inside and outside of the educational environment. All three might, through reflection and action, through praxis, change enough in their environment to make radical changes in their teaching life. 
Of course, what we imagine here is only speculation on our part. We have not had the chance to discuss these ideas further with the participants but this discussion does open up the possibility that enacting can result in actual changes in the teachers' environments.

\section{Conclusion}

In the arts-based educational arena many authors ruminate on the opening of spaces for students in classroom (see e.g. Burnaford, Aprill \& Weiss, 2001; Rabkin \& Redmond, 2004; Stevenson \& Deasy, 2005) through the use of arts-based approaches and integration orientations for illumination and self-knowledge. Fewer have turned the arts-based approaches toward opening such spaces for teachers. This venture into reflective arts inquiry attempts to do just that. Opening spaces within which teachers are encouraged to undergo their own transformations through the arts is a promising avenue for the aims of professional development.

We began this project with the idea of unearthing unconscious ideas by working an artistic image in a way that might aid teachers in plumbing the depths of their teaching lives. We proposed and carried out a three-phase process including, Imaging, Reframing, and Enacting. We used data to see how and in what ways such a process uncovered new ideas, helped teachers see educational phenomena differently, and brought ideas about teaching that might have been buried in the unconscious to conscious awareness. Inevitably the reflective art inquiry process intends to improve practice, either through affecting thinking and feeling on the part of teachers; through allowing teachers who have uncovered new ideas to "live in the tension" created by this new knowledge; or, through directing action in changing aspects of the educational environment.

\section{Notes}

1. For example, a person may know that a wheelbarrow is used to haul materials from one place to another or may, along with William Carlos Williams, know that:

so much depends

upon 
a red wheel

barrow

glazed with rain

water

beside the white

chickens (Williams 1973, p. 97)

In short, ontological knowing consists of a "diffuse apprehension of reality" (Oliver and Gershman 1989, p. 3) that sets off an endless stream of associations, connotations, and images.

2. All names in this article are pseudonyms.

\section{References}

Burnaford, G., Aprill, A., Weiss, C., \& Chicago Arts Education Partnership (Eds.). (2001). Renaissance in the classroom: Arts integration and meaningful learning. Mahwah, $\mathrm{NJ}$ : Lawrence Erlbaum Associates.

Connelly, F. M., \& Clandinin, D. J. (Winter 1994). Telling teaching stories. Teacher Education Quarterly, 21(1), 145-58.

Davis, R. H. (2003). Jung, Freud, and Hillman:Three depth psychologies in context. Westport, CT: Praeger.

Dewey, J. (1934). Art as experience. New York: Perigee Books.

Easthope, A. (1999). The unconscious. New York: Routledge.

Eisner, E. W. (1997). The enlightened eye: Qualitative inquiry and the enhancement of educational practice ( $2^{\text {nd }}$ ed.). Columbus, Ohio: Prentice Hall.

Freire, P. (1970). Pedagogy of the oppressed. New York: Continuum.

Fullan, M. (2007). The new meaning of educational change. (4th ed.). New York: Teachers College Press.
Grumet, M. (1976). Existential and phenomenological foundations. In W. Pinar \& $M$. Grumet (Eds.), Toward a poor curriculum. (pp.111-146). Dubuque, IA: Kendall Hunt.

Grumet, M. (1988). Bitter milk: Women and teaching. Boston: University of Massachusetts Press.

Hillman, J. (1975). Re-visioning psychology. New York: Harper \& Row.

Hillman, J. (1989). A blue fire. New York: Harper \& Row.

Hillman, J. (1996). The soul's code. New York: Random House.

Mayes, C. (2005). Jung and education: Elements of an archetypal pedagogy. Lanham, MD: Rowman \& Littlefield Education.

McDonald, J. (1992). Teaching: Making sense of an uncertain craft. New York: Teachers College Press.

Oliver, D.W., \& Gershman, K. W. (1989). Education, modernity, and fractured meaning: Toward a process theory of teaching and learning. Albany: State University of New York Press. 
Palmer, P. J. (2004). The hidden wholeness: The journey toward the undivided life. New York: Jossey-Bass.

Rabkin, N. \& Redmond, R. (Eds.) (2004). Putting the arts in the picture: Reframing education in the $21^{\text {st }}$ century. Chicago, IL: Columbia College Chicago.

Schwab, J. (1972). The practical: A language for curriculum. In D. Purpel \& M. Belanger (Eds.), Curriculum and the cultural revolution (pp. 287-321). Berkeley: McCutchan.

Shöen, D. A. (1983). The reflective practitioner: How professionals think in action. New York: Basic books.

Stevenson, L.M. \& Deasy, R. J. (2005). Third space: When learning matters. Washington D.C.: Arts Education Partnership.

Tyler, L. (1958). Psychoanalysis and curriculum theory. The School Review 66(4): 446-460.
Uhrmacher, P. B. (1993). Presentational action research. Paper presented at the annual meeting of the American Education Research Association, Atlanta, GA.

Uhrmacher, P. B. (1995). Presentational action research: An analysis. Paper presented at the annual meeting of the American Education Research Association, San Francisco, CA.

Uhrmacher, P.B. \& Trousas, C. (2007, October). Artistry and action: Using arts-based action research for educational inquiry. Paper presented at the annual meeting of the American Association for Teaching and Curriculum, Cleveland, $\mathrm{OH}$.

Williams, W.C. (1973). The Red Wheelbarrow. Poetry: The Norton introduction to literature. J. P. Hunter (ed.). New York: W. W. Norton \& Company.

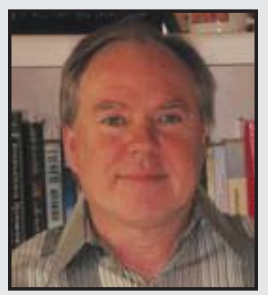

P. Bruce Uhrmacher is Professor of Education at the Morgridge College of Education at the University of Denver. His research interests include the study of alternative educational settings and the use of arts-based research. He is the coeditor of Intricate palette: Working the ideas of Elliot Eisner. Uhrmacher is also the faculty advisor to the Aesthetic Education Institute of Colorado, which holds arts-based learning workshops for teachers each summer.

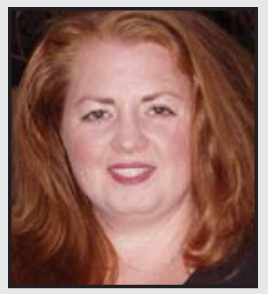

Cassandra Trousas is a doctoral student in Curriculum and Instruction at the Morgridge College of Education at the University of Denver. She is currently completing her dissertation entitled: Teacher artistry and the not-so-still life of arts-centered school reform. She has written a qualitative evaluation of the Harmony Project, an arts-based curriculum program within Denver Public Schools. Trousas has presented papers on artsbased research and arts-centered school reform at the American Association of Teaching and Curriculum and the American Educational Research Association. 